\section{Fishery threatens protected ocean}

The Ross Sea in the Antarctic is the planet's last pristine ocean area, but it could soon become a victim of the race for natural resources at the poles (Nature 478, 174-177; 2011). The region's absolute protection against fishing is being reconsidered by the New Zealand government.

One reason is the demand for a luxury seafood item, the Antarctic toothfish Dissostichus mawsoni - a fishery worth NZ\$18 million (US\$14 million) a year. However, this fish grows slowly and may not spawn every year, so harvesting would be unsustainable.

The designation of the entire Ross Sea as a Marine Protected Area will be debated in November 2012. New Zealand's probable veto was leaked in an official document made public on 11 October (see go.nature. com/ngtelo). The document reveals that the United States, once supportive of Ross Sea protection, is likely to back the New Zealand veto. This has prompted speculation that the move might encourage New Zealand's support for future US ownership claims over Antarctic territories.

A short-sighted refusal by two wealthy nations to protect the Ross Sea's intact marine ecosystem would deprive scientists of invaluable data because its complex structure would be altered forever.

Polar scientists, backed by oceanographer Sylvia Earle, are opposing fishing activities that could remove key species from the ocean's delicately balanced marine food webs. But so far, science-based advocacy for protecting the entire Ross Sea has been glaringly ignored by politicians.

Amélie Lescroël University of Rennes and the National Museum of Natural History, UMR7204, Rennes, France. amelie.lescroel@univ-rennes1.fr David Grémillet Centre for
Functional and Evolutionary Ecology, CNRS, UMR5175, Montpellier, France; and PFIAO, DST/NRF Centre of Excellence, University of Cape Town, South Africa.

\section{Women: sexist fiction is alienating}

What a surprise to learn that the talent of women for locating objects while shopping comes not from years of experience of domestic chores while our menfolk go hunting for the latest electronics, but from an innate ability to access "womanspace" in parallel universes (E. Rybicki Nature 477, 626; 2011). Perhaps this explains why our gender is so poorly represented in engineering and the physical sciences - we have been operating under an entirely different set of physical principles.

Joking aside, it is hard to laugh off implications that routine domestic duties involve mysterious rites known only to women, and that only men are reliable observers who can make scientific discoveries.

Rybicki's story reflects the pernicious prejudice that biology inherently limits women's success at the highest levels of government, business and science. In our view, it is distasteful to publish fiction that promulgates such sexist notions, even if it was written tonguein-cheek. We should instead be encouraging the dissolution of the last bastions of 'manspace'.

Ylaine Gerardin, Tami Lieberman Harvard University, Cambridge, Massachusetts, USA. gerardin@fas.harvard.edu

\section{Women: latent bias harms careers}

Ed Rybicki’s Futures story describes his own helplessness in the face of everyday obstacles (Nature 477, 626; 2011). Although he sees himself as supportive of women scientists, an unintentional, subconscious bias is implied. Such bias can subvert the career path of women - something our community must get to grips with.

The story places women and men in fundamentally different categories: women are well organized and domestically oriented, whereas men are useless in everyday life but come up with theories about the Universe. It is this subconscious categorization that can hurt women as they climb the academic ladder.

Things are better for female scientists now than they were a few decades ago, as overt sexism is slowly dying out. I am hopeful that subconscious bias will follow. Search committees, for instance, could bring these issues out into the open before interviewing candidates for jobs.

Pieter van Dokkum Yale

University, New Haven,

Connecticut, USA.

pieter.vandokkum@yale.edu

\section{Research council will support excellence}

The UK Engineering and Physical Sciences Research Council (EPSRC) met last month to discuss calls for further consultation before announcing changes to its funding strategy (Nature 477, 514; 2011).

We wish to correct several misunderstandings that exist within the research community.

Research excellence remains pre-eminent and the Council will continue to support applications that are deemed excellent by peer review. We have introduced "national importance" as an additional criterion, but this will not override research excellence.

In deciding which of the areas within our budget we want to grow, maintain or reduce, there are no research areas that we shall completely withdraw from funding. A proposal based on outstanding research will be funded in any area.

Our strategy for supporting training and fellowships will be more targeted, but it will provide flexibility for both individuals and institutions.

We shall continue to work with our advisory teams, stakeholders and research leaders to ensure that we optimize the deployment of our limited resources.

David Delpy, John Armitt Engineering and Physical Sciences Research Council, Swindon, UK. david.delpy@epsrc.ac.uk

\section{Risk assessment for Brazil's GM bean}

Your report on the production of genetically modified (GM) beans in Brazil implies that I am an opponent of genetic engineering (Nature 478, 168, 2011). However, you misrepresent my scientific and professional record.

I have never said or written anything against transgenic crops per se. Neither have I claimed to be an opponent of the transgenic technique. However, I have always insisted, as a former member of the Brazilian National Technical Commission on Biosafety (CTNBio) and in my capacity in other professional positions, on critical riskassessment studies and on research meeting a minimum standard of scientific quality.

This is because proper dossiers from the technology proponents are never presented to the CTNBio or the scientific community. In the case of the transgenic pinto bean from EMBRAPA, the agriculture ministry's research arm, neither of these requirements was met. Rubens Onofre Nodari Federal University of Santa Catarina, Florianópolis, Brazil. nodari@cca.ufsc.br

CONTRIBUTIONS

Correspondence may be sent to correspondence@ nature.com after consulting the author guidelines at go.nature.com/cmchno 